\title{
Design of 4-DOF adjusting device for Air Duct Rotary bending fatigue testing machine Tailstock
}

\author{
ZHANG lingyun ${ }^{1, a,}$ PIAO xiaodong ${ }^{2, b}$ \\ ${ }^{1}$ Key Lab of Fundamental Science for National Defense of Aeronautical Digital Manufacturing \\ Process, Shenyang Aerospace University, 110136, China \\ ${ }^{2}$ Key Lab of Fundamental Science for National Defense of Aeronautical Digital Manufacturing \\ Process, Shenyang Aerospace University, 110136, China \\ azhangly79@163.com,,825163309@qq.com
}

\begin{abstract}
Key words: Air duct; Rotary bending fatigue; 4-DOF adjustment
Abstract:In order to improve the accuracy of the air duct rotating bending fatigue life test, basing on the related standards of aviation ministry and other types of rotary bending fatigue machines tailstock home and abroad, a 4-DOF adjusting device, which can move along $\mathrm{X}$ and $\mathrm{Y}$ axis in the horizontal plane and along $\mathrm{Z}$ axis in the vertical plane and rotate around $\mathrm{Z}$ axis, is designed. The tailstock can realize the experiment of different diameter and bending Angle rotating bending fatigue experiment was carried out at the same time ${ }^{[2]}$. It improves the test efficiency, enhances the universality and plays a leading role for the design of the domestic similar products.
\end{abstract}

\section{Introduction}

It involves many hydraulic transmission systems in The process of designing aircraft. the length of the hydraulic pipeline will directly affect the safety of the aircraft ${ }^{[3]}$. A new type of hydraulic conduit connecting technology is used to connect the hydraulic conduit without flaring. Due to its unique and novel connection method and no fixed reference data, it must be tested to ensure its safety. The single function and limited accuracy for the existing domestic rotary bending fatigue testing machine tailstocks is common ${ }^{[1]}$. So it is necessary to design a tailstock adjustment device for a rotary bending fatigue testing machine which satisfies both the accuracy requirement and the various degrees of freedom adjustment function. Referencing to the Ministry of Aviation aircraft hydraulic pipe and its connection bending fatigue test standards (HB6442-90), learning from similar products' design home and abroad, combining with the particularity of air pipe without flaring connection test tube, a tailstock adjustment device is designed, which can simultaneously achieve 4-DOF adjustment namely, $\mathrm{Y}$-axis, $\mathrm{Z}$ axis and rotation around the $\mathrm{Z}$ axis along the $\mathrm{X}$ axis. It improves the accuracy of the test.

\section{Overall Design of Tailstock Adjustment Device}

referencing to the relevant standards, the character of rotary bending fatigue testing machine tailstock adjustment device is that can simultaneously achieve 4-DOF adjustment, involving moving along the $\mathrm{X}$ axis, $\mathrm{Y}$ axis, $\mathrm{Z}$ axis and rotation around the $\mathrm{Z}$ axis. The overall design shown in Figure 1: The tailstock adjustment device consists of mounting seat, slide table, tailstock and mandrel ${ }^{[4]}$. 


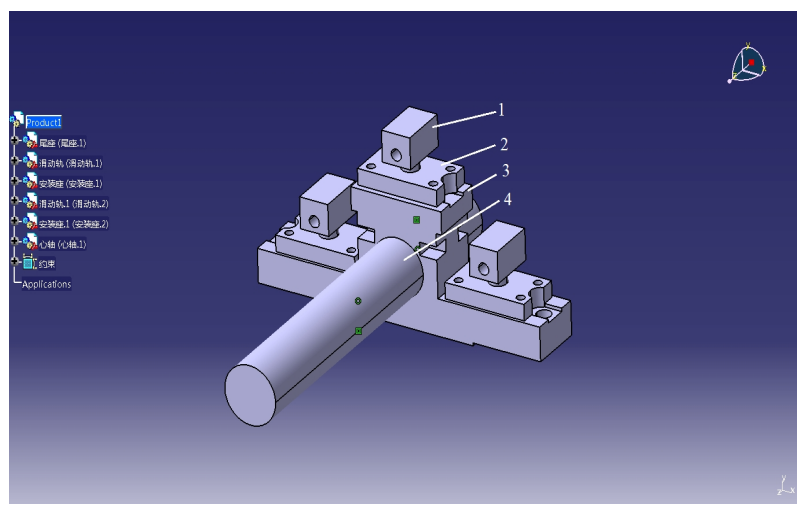

Figure 1 rotary bending fatigue testing machine tailstock adjustment device structure diagram

1.Mounting seat

3. Tailstock
2. slide table

4. Mandrel

The mounting seat is fixed on the rail table surface so that can realize the movement along the $\mathrm{Z}$-axis in vertical plane and the rotation around the $\mathrm{Z}$-axis. The mounting seat and the slide rail table are assembled as a whole on the tailstock so that can realize the movement along the Y-axis. Two tailstocks and mandrel are assembled and placed at both ends of the air duct bending fatigue testing machine so that can realize the movement along the $\mathrm{X}$-axis direction ${ }^{[4]}$.

\section{the structure Design of Key Components}

(a) Mounting seat. As shown in Figure 2, the mount assembly is constituted by Mounting seat and Adjusting nut. The test tube's movement along the $Z$-axis direction in vertical plane is realized by adjusting the adjusting nut in the test and the rotation around the $\mathrm{Z}$ axis is achieved by rotating the mounting seat ${ }^{[6]}$.

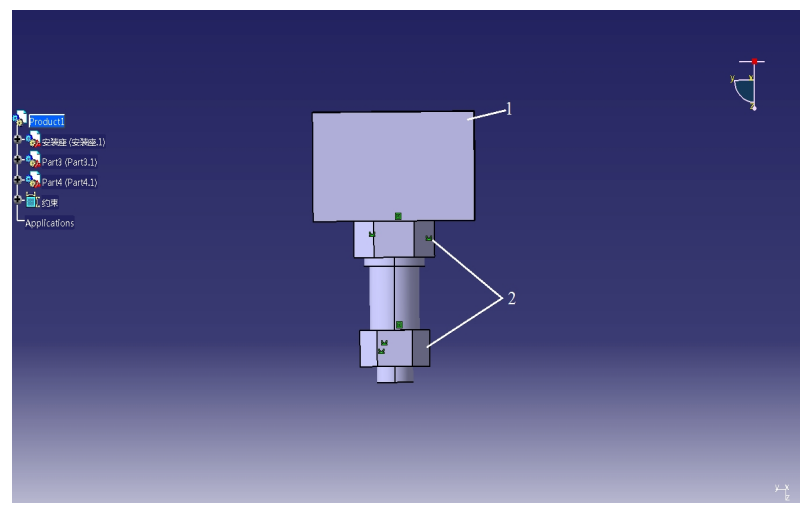

Figure 2 Schematic illustration of the mounting seat assembly

(b) Slide table. As shown in Figure 3, slide rail is assembled through the bottom of the U-shaped table and the U-shaped groove of tailstock platform, positioned by the bolt. In the test the movement along Y-axis in horizontal plane is realized by the connection of the groove and table. 


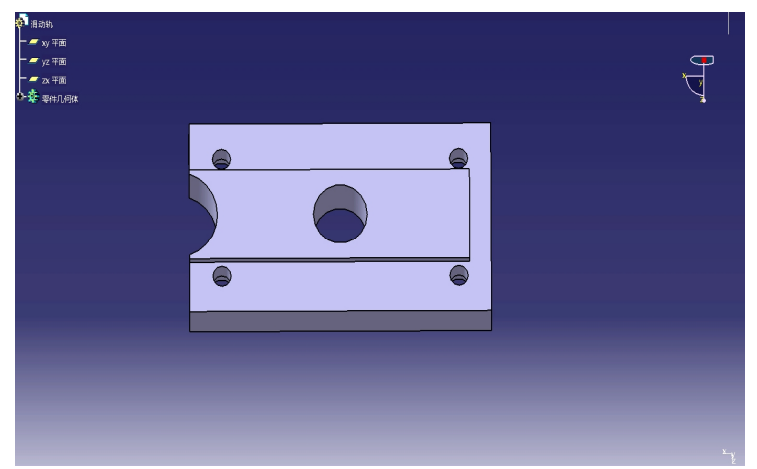

Figure 3 Schematic illustration of the Slide table

(c) Tailstock. As shown in Figure 4, the tailstock, which has hole in its center and is equipped with a linear bearing, realize coaxial positioning through assembled with the mandrel. The tailstock and mandrel are assembled and placed at both ends of the air duct bending fatigue testing machine so that can achieve the movement along $\mathrm{X}$-axis direction.

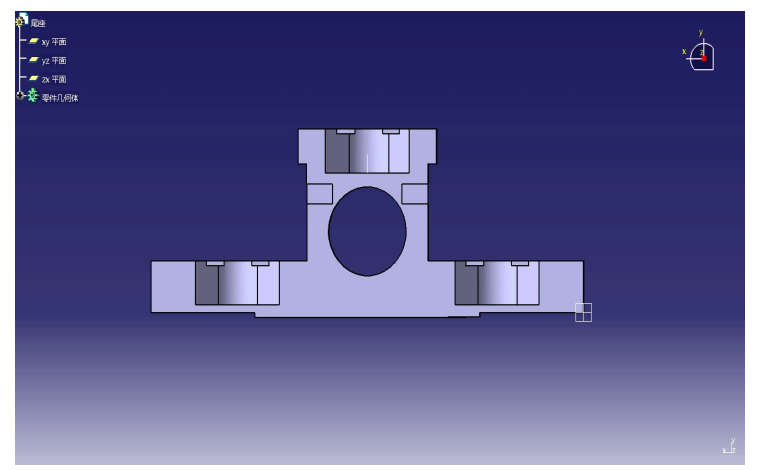

Fig.4

\section{Rotating bending fatigue test}

The tailstock 4-DOF adjustment device of air duct rotary bending fatigue testing machine has completed production and acceptance in May 2016. During the acceptance process, due to the tailstock 4-DOF adjustment device's multi-function and high precision features, the test machine can be an effective test for all elbows. It does not only solve the problem of bending fatigue test, but also improve the utilization of the testing machine ${ }^{[8]}$. The assembly of the sliding bearing between tailstock and mandrel makes the test more conveniently and faster. Several sets of pipe fittings have been tested and the test effect is much higher than in the past. The actual working diagram is shown in Figure 5.

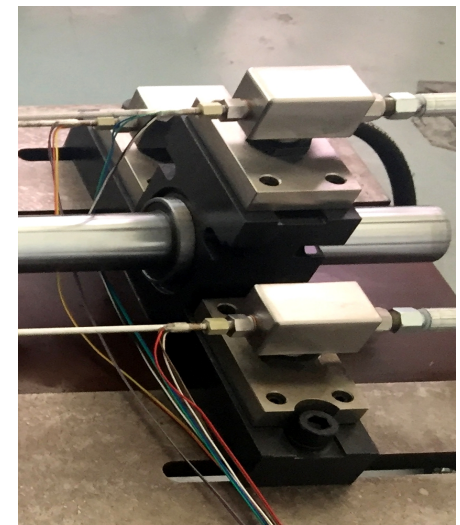

Figure 5 Tailstock 4-DOF adjusting device working figure 


\section{Conclusions}

The development of the tailstock 4-DOF adjustment device of the testing machine successfully completes the design goal by basing on the advantages of the existing equipment home and abroad and combining with the characteristics of the test requirements. simple and compact designing structure, convenient assembly, 4-DOF adjusting function which involves the movement along $\mathrm{X}$-axis and $\mathrm{Y}$-axis directions in horizontal plane and the movement along $\mathrm{Z}$-axis direction in vertical plane and the rotation around Z-axis, all these help the device improve the scope of equipment and versatility, and improve the test accuracy. Based on this devise, Different diameter and different bending angle of the test pieces can be tested at the same time. It improves the efficiency of the experiment and reduces the cost and product preparation cycle. The entire adjustment device achieves the maximum combination of function and efficiency in a limited space from the design concept. It will have a certain role in inspiration for the development of similar product.

\section{References}

[1] WANG Liang-mo,CHEN Yu-fa,WANG Chen-zhi,WANG Qing-zheng. Simulation and Test on Aluminum Alloy Wheel Rotary Fatigue Life [J]. JJournal of Nanjing University of Science and Technology(Natural Science),2009 (5),571-575.

[2] LI Jun,WANG Zhi-ming,CAI Qing-nan. Study of Multi-function Impact Test Machine Based on Wheeled Child Conveyance[J]. Machine Building \& Automation,2009 (5): 18-19.

[3] HB6224-1990. Aircraft Hydraulic Pipes and Their Connections Bending Fatigue Test Standard $[\mathrm{S}]$.

[4] Cheng Daxian.Handbook Of Mechanical Design [M]. Beijing: Chemical Industry Press, 2002.

[5] V.Gao. Disc Machine Testing to Assess the Life of Surface-Damaged Railway Track. Proceedings of the Institution of Mechanical Engineers. 2001, 215(4): 261-275

[6] N. Soret, J. P. Bernadou, S. Marsac. A Biaxial Fatigue Testing Machine for Thin-Walled Tubes Under Axial Load and Internal Pressure at Elevated Temperatures. International Journal of Fatigue. 1996, 18(8): 609 611

[7] K. Takashima, M. Shimojo, S. Sugiura. Fatigue Testing Machine of Micro-Sized Specimens for MEMS Applications. Materials Research Society Symposium-Proceedings.2000,(605): $241 \sim 246$

[8] C. C. Lawrence. Triaxial Fatigue Testing Machine for Polymeric Materials.Journal of Strain Analysis for Engineering Design. 1980, 15(3): 159 173

[9] M. Z. Shah, S. J. Alkemade, G. M. Weston etc. Variable Amplitude Fatigue Testing of a High Hardness Armour Steel. International Journal of Fatigue. 1998, 20(3): 233 239 